\section{BMJ Open Ophthalmology}

\title{
Visual performance in a flight simulator: multifocal intraocular lenses in pilots
}

\author{
Lee Lenton
}

To cite: Lenton L. Visual performance in a flight simulator: multifocal intraocular lenses in pilots. BMJ Open Ophthalmology 2018;3:e000139. doi:10.1136/ bmjophth-2017-000139

Received 21 December 2017 Revised 2 May 2018 Accepted 9 May 2018
Check for updates

Vision Eye Institute Clinic, Brisbane, Queensland, Australia

\section{Correspondence to} Dr Lee Lenton, Vision Eye Institute Clinic, Brisbane, QLD 4066, Australia; lee.lenton@live. com.au

\section{ABSTRACT}

Objective To compare the performance of adults with multifocal intraocular lenses (MIOLs) in a realistic flight simulator with age-matched adults with monofocal intraocular lenses (IOLS).

Methods and Analysis Twenty-five adults $\geq 60$ years with either bilateral MIOL or bilateral IOL implantation were enrolled. Visual function tests included visual acuity and contrast sensitivity under photopic and mesopic conditions, defocus curves and low luminance contrast sensitivity tests in the presence and absence of glare (Mesotest II), as well as halo size measurement using an app-based halometer (Aston halometer). Flight simulator performance was assessed in a fixed-based flight simulator (PS4.5). Subjects completed three simulated landing runs in both daytime and night-time conditions in a randomised order, including a series of visual tasks critical for safety.

Results of the 25 age-matched enrolled subjects, 13 had bilateral MIOLs and 12 had bilateral IOLs. Photopic and mesopic visual acuity or contrast sensitivity were not significantly different between the groups. Larger halo areas were seen in the MIOL group and Mesotest values were significantly worse in the MIOL group, both with and without glare. The defocus curves showed better uncorrected visual acuity at intermediate and near distances for the MIOL group. There were no significant differences regarding performance of the vision-related flight simulator tasks between both groups.

Conclusions The performance of visually related flight simulator tasks was not significantly impaired in older adults with MIOLs compared with age-matched adults with monofocal IOLs. These findings suggest that MIOLs do not impair visual performance in a flight simulator.

\section{INTRODUCTION}

Cataract is one of the major causes of reversible visual impairment in older adults. ${ }^{1}$ While standard intraocular lenses (IOLs) have a single focus (monofocal), advances in technology led to multifocal intraocular lenses (MIOLs) that address the visual limitations of monofocal IOLs at near and intermediate distances, providing functional vision and lower spectacle dependency across distances. $^{2-5}$ However, side effects have been reported for MIOLs, such as decreased contrast sensitivity, glare disability and halos, that might impact the patient's performance on everyday tasks, particularly under low light conditions. ${ }^{3}$

\section{Key messages}

What is already known about this subject?

- The Australian Civil Aviation Safety Authority (CASA) suggests that multifocal contact lenses and multifocal intraocular lenses (MIOLs) 'cause unacceptable impairment of vision', withholding subjects with such lenses from holding a pilot's license.

\section{What are the new findings?}

This is the first study on flight simulator performance of individuals with MIOLs. Our findings suggest that the performance of vision-related flight simulator tasks was not significantly impaired in subjects with MIOLs relative to that of age-matched monofocal IOL subjects.

\section{How might these results change the focus of research or clinical practice? \\ Our study results could contribute to a revision of the CASA guidelines in that subjects with MIOLs become legally eligible to hold a pilot's license.}

An area that has attracted particular interest in terms of the functional implications of MIOLs is the vision requirement for pilots. The Australian Civil Aviation Safety Authority (CASA) suggests that multifocal contact lenses and MIOLs 'cause unacceptable impairment of vision'. 'This ruling has been widely upheld, but until now there is a lack of direct evidence to suggest that pilots with MIOLs will experience greater visual difficulties than age-matched subjects with monofocal IOLs, for whom there are no flight restrictions.

The aim of this study was to compare the performance of MIOL subjects with age-matched IOL subjects in a realistic flight simulator.

\section{METHODS}

Subjects

Twenty-five subjects, 60 years or older, were enrolled in the study after previous uncomplicated bilateral cataract surgery, with implantation of either monofocal (monoIOL group) or multifocal IOLs (MIOL group). Subjects were recruited from the patient 
database of the author (LL), an experienced cataract surgeon.

The study adhered to the tenets of the Declaration of Helsinki and was approved by the Queensland University of Technology Human Research Ethics Committee. All subjects attended two testing sessions.

\section{Visual function assessment}

Binocular distance visual acuity was tested using high-contrast ETDRS charts at $4 \mathrm{~m}$ under mesopic luminance $\left(0.75 \mathrm{~cd} / \mathrm{m}^{2}\right)$ with dimmed room lighting (3lux) and under photopic luminance $\left(108 \mathrm{~cd} / \mathrm{m}^{2}\right)$ with high room lighting (440lux). Visual acuity was scored in logMAR, using three different ETDRS charts.

Binocular contrast sensitivity was measured binocularly at $3 \mathrm{~m}$ with the Pelli-Robson test under the same mesopic and photopic lighting conditions as for visual acuity. Contrast sensitivity was scored in $\log$ CS. Two different charts were used.

Binocular distance defocus curves were measured using high-contrast ETDRS charts at $4 \mathrm{~m}$. Defocus was sequenced from +1.50 to $-5.00 \mathrm{dpt}$ in $0.50 \mathrm{dpt}$ steps over subjects' habitual distance correction, and the letter charts alternated for each measurement.

Binocular mesopic contrast sensitivity (without and with glare) was tested using the Mesotest II. ${ }^{7}$ The contrast of the target varied by $0.1 \log$ units, corresponding to $95 \%$, $80 \%, 63 \%$ and $50 \%$ of the contrast threshold and was conducted without (background luminance of $0.032 \mathrm{~cd}$ / $\left.\mathrm{m}^{2}\right)$ and with a glare source $(0.35$ lux at the pupil, located three degrees to the left of target; background luminance of $\left.0.1 \mathrm{~cd} / \mathrm{m}^{2}\right)$.

Five presentations were tested at each of the four contrast levels, without and with the glare source. The total number of errors was calculated.

For halometry, the halo produced by glare from a bright white LED attached to the centre of an iPad screen (iPad4, www.apple.com) was determined as the position closest to the LED where two out of three presentations of a randomly presented high contrast 20/50 letter $(0.4$ $\log$ MAR) were correctly identified. ${ }^{8}$ A seen-to-not-seen approach was used with a 0.1-degree step size along eight meridians. The halo area (deg2) was determined by calculating the area of the halo surrounding the LED glare source.

The NeurOptic pupillometer (model 79101; NeurOptics) was used to measure pupil size in both eyes under photopic and mesopic lighting conditions.

The subjects also completed a validated questionnaire on their self-reported quality of vision $(\mathrm{QoV}){ }^{9}$ This included questions relating to the quality of their distance and reading vision, with glasses if they wore them, both during the day and at night. A series of questions asked about the frequency and severity of symptoms experienced during everyday activities in the past week, for example, glare, haloes, double vision and focusing difficulties. ${ }^{9}$ To reduce the possibility of inconsistent responses, this questionnaire includes $\mathrm{QoV}$ pictures to characterise the different visual symptoms. Finally, subjects reported whether they achieved spectacle freedom following their surgery, for distance, intermediate and near activities.

\section{Flight simulator assessment}

All subjects also completed one session assessing their vision-related flight simulator performance at Aviation Australia, near Brisbane Airport. The fixed-based simulator (PS4.5) (https://brisbane.flightexperience.com. $\mathrm{au} /$ the-simulator/) is based on the Boeing 737-800. The simulator has received certification for pilot training from the Federal Aviation Administration (USA), Civil Aviation Safety Authority (Australia), Civil Aviation Authority New Zealand (New Zealand) and Department of Civil Aviation (Indonesia).

Subjects were seated in the co-pilot seat and completed six simulated landing runs in clear daytime and clear nighttime conditions, each of which took approximately $5 \mathrm{~min}$. The Airport Approach spotlight was set at around 330 lux for the daytime and around 50 lux for the night-time run. The order of the light conditions was counterbalanced between subjects within each IOL group. In order to exclude the possibility of a training effect, no flight simulator training was previously performed in both groups.

Subjects were instructed to wear whatever refractive spectacle correction they would use habitually for near to intermediate distances in the simulator. During each run, subjects were asked to complete a series of critical visual tasks for safety as highlighted in figure 1, both within (in the front and side console) as well as external to the cockpit as the plane approached the landing strip. The following pre-flight and in-flight visual tasks at far, intermediate $(80$ to $120 \mathrm{~cm})$ and near $(40$ to $50 \mathrm{~cm})$ distances were tested:

\section{Pre-flight visual tasks}

At the beginning of each run, the pilot positioned the plane 10 miles from Sydney airport and froze its position. Subjects were then asked to complete the following tasks:

- Radio frequency task: Report the three active or stand-by radio frequency values in the centre console to the left of their seat. The size equivalent of this task was around 6/40 Snellen visual acuity.

- Airport approach task: Report one ALT (altitude) value corresponding to a DME (distance measuring equipment) DIST (distance) value from the paperbased Airport Approach Chart positioned directly to their right near the window. The size equivalent of this task was around 6/15 Snellen visual acuity.

\section{In-flight visual tasks}

The subjects then commenced the descent into Sydney airport. During this descent, subjects were asked to complete the following tasks:

- Screen-based console tasks: Report the heading, speed, altitude and fuel-flow values off the console at regular intervals. The size equivalent of these tasks 


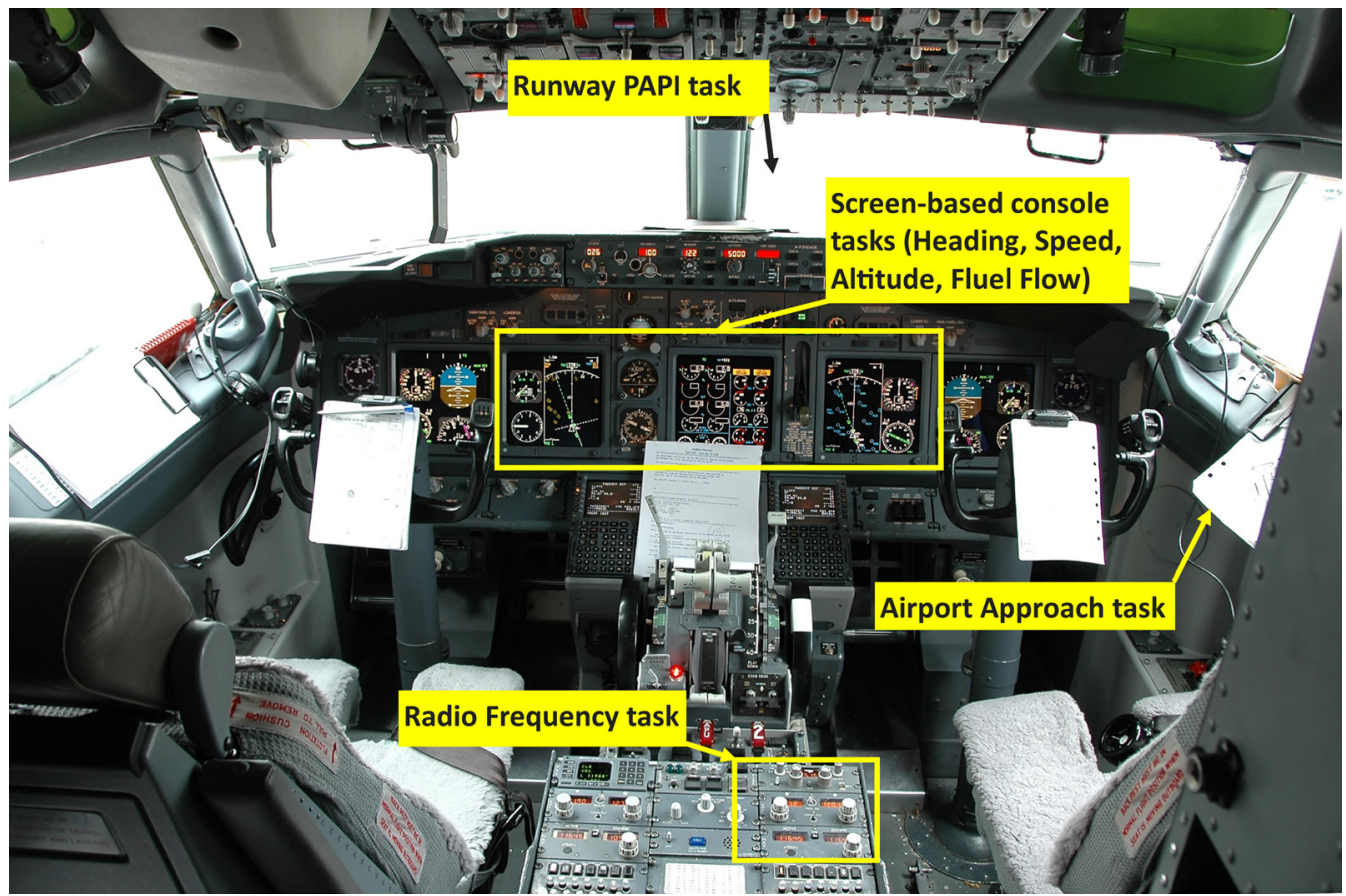

Figure 1 Internal view of the PS4.5 simulator with visual tasks to be completed for the study. PAPI, precision approach path indicator.

ranged from $6 / 18$ to around 6/30 Snellen visual acuity.

- Airport approach task: The size equivalent of this task was around 6/15 Snellen visual acuity.

- Runway precision approach path indicators (PAPI) task: Report the colours of the four PAPI lights on the right side of the runway as the plane prepared for landing at regular intervals. There are four lights either side of the landing strip, and these can be presented as any combination of red and white lights.

One GoPro camera was mounted on the yoke within the simulator, which recorded the various values on the console and was used to assist with post-simulator scoring as required.

\section{Data analysis}

Statistical analyses were performed using SPSS V.23.0, and the level of significance was set at $\mathrm{p}=0.05$.

Descriptive statistics were used to analyse the demographic and questionnaire. Normality of data samples was evaluated by means of the Kolmogorov-Smirnov test. Intergroup comparisons of categorical characteristics were performed using Fisher's exact test. Independent t-tests were used to compare between-group differences in the visual function tests and flight simulator performance measures. Otherwise, when parametric analysis was not possible, the Mann-Whitney U test was applied for comparisons between the two groups.

Sample size was calculated with a binary outcome non-inferiority test for the parameter whether the patients pass the CASA vision requirements for a Class 1 and 2 pilot license. If there is a true difference in favour of the experimental treatment of $25 \%$, then 26 patients are required to be $80 \%$ sure that the upper limit of a one-sided $95 \%$ CI will exclude a difference in favour of the standard group of more than $15 \%$."

\section{Results}

Twenty-five adults participated in the study, 13 had bilateral MIOLs (mean age 68.1 \pm 6.4 years, nine men) and 12 had bilateral monofocal IOLs (mean age 69.8 \pm 5.7 years, three men). There were no significant differences in age between the two groups $(\mathrm{p}=0.47)$.

All subjects in the MIOL group had the same lens model implanted in both eyes, the AT LISA tri 839MP (CZM, Jena, Germany) with powers between 16 and $30 \mathrm{dpt}$, and two subjects had the toric version. Implantations had taken place at least 1 year before enrolment in the study. Subjects in the monoIOL group had bilateral or mixed implantations of the following IOL models: CT ASPHINA 409MP (CZM), Acrysof SN60WF, Acrysof SN60AT, Acrysof SN6802 and Alcon SN60T3 (Alcon, Ft. Worth, Texas, USA).

\section{Visual performance results}

Visual performance results are shown in table 1. There were no significant differences in the self-reported quality of vision between the multifocal and monofocal IOL groups, for either distance or reading vision during the day and at night ( $p>0.33$ ).

The MIOL group had a significantly higher incidence of halos compared with the monoIOL group $(\mathrm{p}=0.019)$. While there was a trend towards greater severity of these haloes in the MIOL group, this did not reach statistical significance $(p=0.06)$. There were no other significant differences in the severity of symptoms between the two groups. 
Table 1 Results of the visual performance tests in both groups

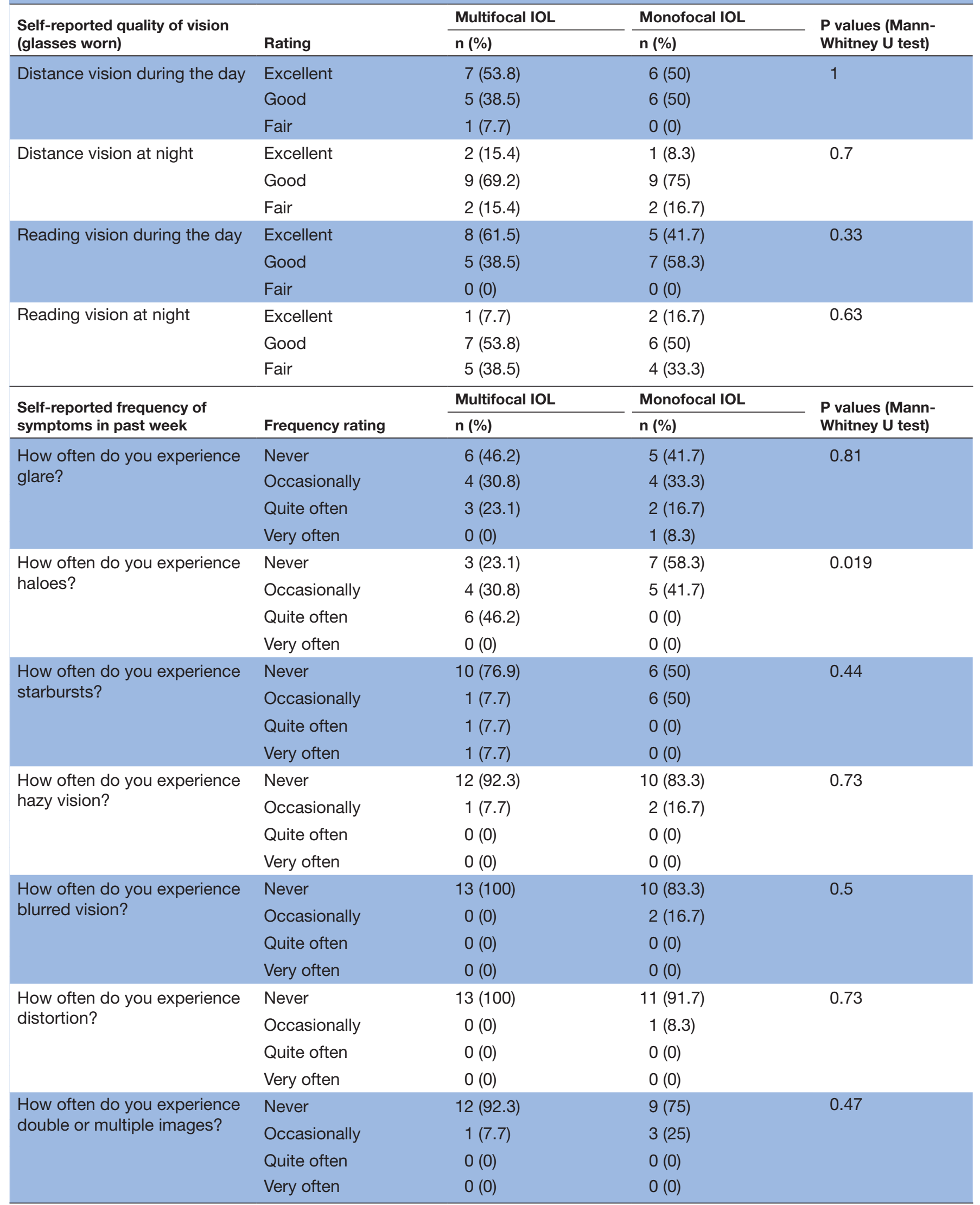


Table 1 Continued

\begin{tabular}{|c|c|c|c|c|}
\hline \multirow{2}{*}{$\begin{array}{l}\text { Self-reported frequency of } \\
\text { symptoms in past week }\end{array}$} & \multirow[b]{2}{*}{ Frequency rating } & \multirow{2}{*}{$\begin{array}{l}\text { Multifocal IOL } \\
\mathrm{n}(\%) \\
\end{array}$} & \multirow{2}{*}{$\begin{array}{l}\text { Monofocal IOL } \\
\mathrm{n}(\%) \\
\end{array}$} & \multirow{2}{*}{$\begin{array}{l}\text { P values (Mann- } \\
\text { Whitney U test) }\end{array}$} \\
\hline & & & & \\
\hline \multirow{4}{*}{$\begin{array}{l}\text { How often do you experience a } \\
\text { fluctuation in your vision? }\end{array}$} & Never & $8(61.5)$ & 10 (83.3) & \multirow[t]{4}{*}{0.38} \\
\hline & Occasionally & $5(38.5)$ & $2(16.7)$ & \\
\hline & Quite often & $0(0)$ & $0(0)$ & \\
\hline & Very often & $0(0)$ & $0(0)$ & \\
\hline \multirow{4}{*}{$\begin{array}{l}\text { How often do you experience } \\
\text { focusing difficulties? }\end{array}$} & Never & $8(61.5)$ & $8(66.7)$ & \multirow[t]{4}{*}{0.85} \\
\hline & Occasionally & $5(38.5)$ & $4(33.3)$ & \\
\hline & Quite often & $0(0)$ & $0(0)$ & \\
\hline & Very often & $0(0)$ & $0(0)$ & \\
\hline \multirow{4}{*}{$\begin{array}{l}\text { How often do you experience } \\
\text { difficulty judging distance or } \\
\text { depth perception? }\end{array}$} & Never & $12(92.3)$ & $11(91.7)$ & \multirow[t]{4}{*}{0.98} \\
\hline & Occasionally & $1(7.7)$ & $1(8.3)$ & \\
\hline & Quite often & $0(0)$ & $0(0)$ & \\
\hline & Very often & $0(0)$ & $0(0)$ & \\
\hline \multirow{2}{*}{$\begin{array}{l}\text { Did the surgery result in you } \\
\text { achieving spectacle freedom? }\end{array}$} & & Multifocal IOL & Monofocal IOL & \multirow{2}{*}{$\begin{array}{l}\text { P values (Fisher's } \\
\text { exact test) }\end{array}$} \\
\hline & Response & $n(\%)$ & $n(\%)$ & \\
\hline \multirow[t]{2}{*}{ Distance } & Yes & $13(100)$ & $12(100)$ & \multirow[t]{2}{*}{1} \\
\hline & No & $0(0)$ & $0(0)$ & \\
\hline \multirow[t]{2}{*}{ Intermediate } & Yes & $13(100)$ & $10(83)$ & \multirow[t]{2}{*}{0.22} \\
\hline & No & $0(0)$ & $2(17)$ & \\
\hline \multirow[t]{2}{*}{ Near } & Yes & $13(100)$ & $4(33)$ & \multirow[t]{2}{*}{$<0.001$} \\
\hline & No & $0(0)$ & $8(67)$ & \\
\hline \multirow{2}{*}{\multicolumn{2}{|c|}{ Visual function test }} & Multifocal IOL & Monofocal IOL & \multirow[b]{2}{*}{$P$ value (t-test) } \\
\hline & & Mean (SD) & Mean (SD) & \\
\hline \multicolumn{2}{|l|}{ Photopic visual acuity (logMAR) } & $-0.06(0.09)$ & $-0.03(0.1)$ & 0.46 \\
\hline \multicolumn{2}{|l|}{ Mesopic visual acuity (logMAR) } & $0.21(0.13)$ & $0.22(0.14)$ & 0.8 \\
\hline \multicolumn{2}{|c|}{ Photopic contrast sensitivity (log units) } & $1.9(0.08)$ & $1.94(0.02)$ & 0.14 \\
\hline \multicolumn{2}{|c|}{ Mesopic contrast sensitivity (log units) } & $1.32(0.13)$ & $1.43(0.29)$ & 0.23 \\
\hline \multicolumn{2}{|l|}{ Near letter visual acuity (logMAR) } & $-0.13(0.07)$ & $-0.21(0.14)$ & 0.08 \\
\hline \multicolumn{2}{|c|}{ Intermediate letter visual acuity (logMAR) } & $0.05(0.08)$ & $0.13(0.14)$ & 0.12 \\
\hline \multicolumn{2}{|c|}{ Mesotest score-without glare (no of errors) } & $9.46(5.94)$ & $4.08(4.32)$ & $0.017^{*}$ \\
\hline \multicolumn{2}{|c|}{ Mesotest score-with glare (no of errors) } & $18.62(2.36)$ & $13(8.11)$ & $0.025^{\star}$ \\
\hline Glare halo area (deg2) & & $1.31(0.63)$ & $0.57(0.28)$ & $0.001^{* *}$ \\
\hline Photopic pupil diameter (averag & ge both eyes) (mm) & $3.08(0.39)$ & $3.24(0.42)$ & 0.33 \\
\hline Mesopic pupil diameter (averag & e both eyes) (mm) & $4.94(0.81)$ & $4.91(0.74)$ & 0.91 \\
\hline
\end{tabular}

IOL, intraocular lens.

There was a trend for greater spectacle freedom for both distance and intermediate activities in the MIOL group compared with the monoIOL group, but these differences were not significant. However, there was a significant difference in spectacle freedom for near activities, with all MIOL subjects reporting spectacle freedom, compared with around $30 \%$ in the monoIOL group $(\mathrm{p}<0.001)$.

There were no significant differences in photopic or mesopic visual acuity $(\mathrm{p}>0.46)$ or photopic or mesopic contrast sensitivity $(p>0.14)$ between the groups.
MIOL subjects performed significantly worse than the monofocal group on both the Mesotest without and with glare, making on average five to six more errors on both $(p<0.025)$. In addition, the halo area size was significantly larger in the MIOL group $(p=0.001)$. No differences were noted in photopic or mesopic pupil size between the two groups.

None of the MIOL group required any additional spectacles to complete the simulator tasks, whereas $2 / 3$ of the monoIOL subjects needed spectacles for near vision. 
Table 2 Visual standards of participants wearing their habitual correction relative to the CASA vision requirements set out in Regulation $67.150^{10}$

$\begin{array}{ll}\text { Multifocal IOL } & \begin{array}{l}\text { Monofocal IOL } \\ (n=13)\end{array}\end{array}$

Monocular VA
requirements (Item 1.35)
Class 1
(6/9 or better in each
eye)
$\begin{aligned} & \text { Class } 2 \\ & (6 / 12 \text { or better in each }\end{aligned}$
eye)

Binocular VA requirements

(Item 1.35)

\begin{tabular}{lll}
\hline $\begin{array}{l}\text { Class } 1 \text { (6/6 or better) } \\
\text { Class } 2 \text { (6/9 or better) }\end{array}$ & All passed & All passed \\
$\begin{array}{l}\text { Intermediate requirements } \\
\text { (Item } 1.36)\end{array}$ & All passed & All passed \\
& $\begin{array}{l}\mathrm{N} 14 \text { binocularly } \\
\text { (with or without } \\
\text { correcting lenses) at a } \\
\text { distance of } 1 \mathrm{~m}\end{array}$ & \\
$\begin{array}{l}\text { Near VA requirements } \\
\text { (Item } 1.36)\end{array}$ & \\
\hline $\begin{array}{l}\text { N5 binocularly in the } \\
\text { range of } 30 \text { to } 50 \mathrm{~cm}\end{array}$ & $1(8 \%)$ failed & $1(8 \%)$ failed \\
\hline
\end{tabular}

CASA, Civil Aviation Safety Authority; IOL, intraocular lens; VA, visual acuity.

The visual function of the subjects was considered in terms of whether they would have passed the CASA vision requirements for a Class 1 and 2 pilot license (table 2). ${ }^{10}$ There was a trend for more monoIOL subjects to fail on the basis of monocular visual acuity, but these differences failed to reach significance for either Class $1(\mathrm{p}=0.294)$ or Class 2 ( $p=0.109)$ licenses. The monoIOL group was also more likely to fail the Class 1 license, but again this difference was not significant $(\mathrm{p}=0.490)$. In summary, there was no significant difference in the number of subjects in either IOL group who would have either passed or failed the CASA visual acuity requirements at any tested distance.

\section{Defocus curves}

The defocus curves for both groups are presented in figure 2. The monoIOL group demonstrated maximum visual acuity without any defocus $(-0.03 \pm 0.1 \log$ MAR) and a gradual decline in acuity with increased defocus in both directions. The MIOL group also demonstrated maximum distance acuity without any defocus $(-0.06 \pm 0.09 \log \mathrm{MAR})$, but there was only a slight reduction in acuity with myopic blur (up to $-3.00 \mathrm{dpt}$ ).

\section{Flight simulator visual performance results}

Table 3 presents the mean flight simulator visual performance data for both groups. There was no significant difference in performance between the groups for any parameter.

\section{DISCUSSION}

In this study, the vision and flight simulator performance of a group of older adults with MIOLs was compared with that of a group of age-matched adults with monofocal IOLs. This comparative study was undertaken to explore concerns that MIOLs have negative effects on functional vision, and specifically, claims by CASA that multifocal contact lenses and IOLs 'cause unacceptable impairment of vision', which precludes individuals with these visual corrections from holding a pilot's license. ${ }^{6}$ Performance was assessed both under daytime and night-time flying conditions, given that night-time flying may be more problematic in those with multifocal lenses given the larger pupils associated with low light levels.

The findings demonstrated that the visual function of the two groups did not differ significantly in terms of their visual acuity or contrast sensitivity, either under photopic or mesopic light conditions, which is in accordance with previous studies. ${ }^{3}$ However, mesopic contrast sensitivity when measured with the Mesotest, both with and without glare, was significantly worse in the MIOL relative to the monoIOL group, which has not been previously

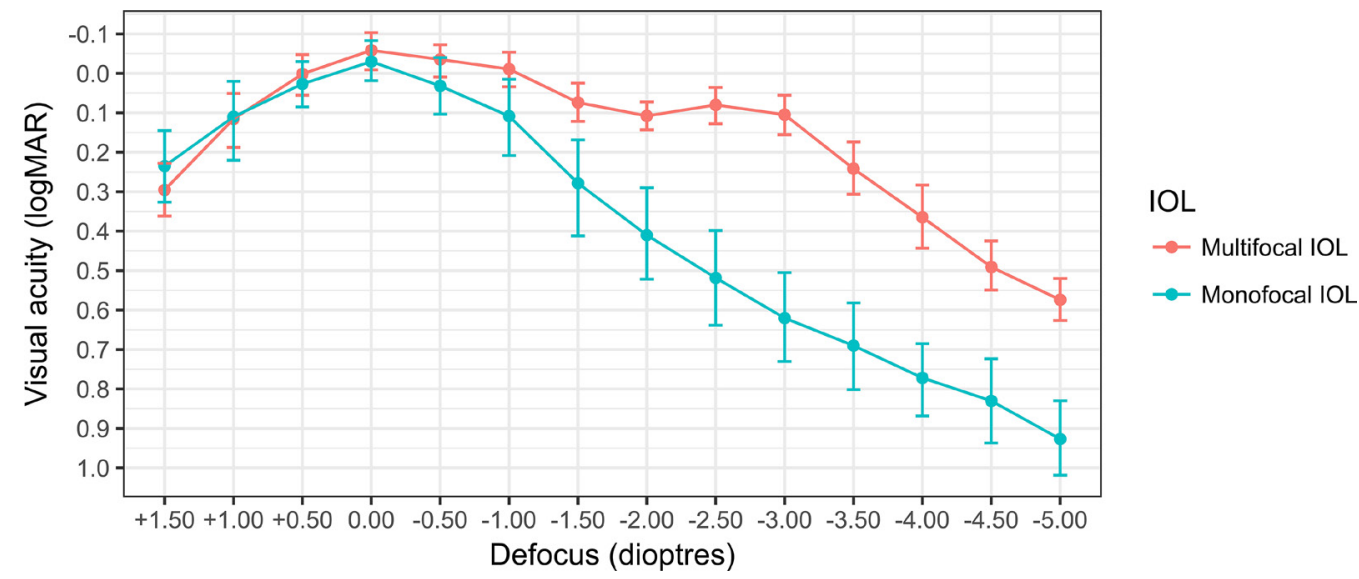

Figure 2 Defocus curve, showing visual acuity across the various levels of defocus for both groups. IOL, intraocular lens. 
Table 3 Comparison of flight simulator visual performance tasks between both groups

\begin{tabular}{|c|c|c|c|c|}
\hline & $\begin{array}{l}\text { Mean number of } \\
\text { opportunities over the } \\
\text { three runs }\end{array}$ & $\begin{array}{l}\text { Multifocal IOL } \\
\text { Mean (SD) }\end{array}$ & $\begin{array}{l}\text { Monofocal IOL } \\
\text { Mean (SD) }\end{array}$ & $P$ values (t-test) \\
\hline \multicolumn{5}{|l|}{ Radio frequencies values } \\
\hline Day (\% correct) & 9 & $97.4(6.7)$ & $100(0)$ & 0.20 \\
\hline Night (\% correct) & 9 & $99.1(3.1)$ & $97.2(5)$ & 0.26 \\
\hline \multicolumn{5}{|l|}{ Landing guide } \\
\hline Day (\% correct) & 6 & $97.4(9.2)$ & $100(0)$ & 0.35 \\
\hline Night (\% correct) & 6 & $93.6(14.5)$ & $97.2(6.5)$ & 0.43 \\
\hline \multicolumn{5}{|l|}{ Screen-based console values } \\
\hline Heading day (\% correct) & 30 & $100(0)$ & $100(0)$ & 1 \\
\hline Heading night (\% correct) & 30 & $99.7(0.9)$ & $100(0)$ & 0.35 \\
\hline Speed day (\% correct) & 30 & $99.7(0.9)$ & $100(0)$ & 0.35 \\
\hline Speed night (\% correct) & 30 & $99.5(1.3)$ & $99.7(1)$ & 0.61 \\
\hline Altitude day (\% correct) & 30 & $96.9(6.6)$ & $98.1(4.8)$ & 0.63 \\
\hline Altitude night (\% correct) & 30 & $93.3(14.6)$ & $98.3(2.7)$ & 0.26 \\
\hline Fuel flow day (\% correct) & 3 & $100(0)$ & $100(0)$ & 1 \\
\hline Fuel flow night (\% correct) & 3 & $100(0)$ & $100(0)$ & 1 \\
\hline \multicolumn{5}{|l|}{ Runway lights } \\
\hline Day (\% correct) & 8 & 33.1 (18.3) & 45 (32.3) & 0.27 \\
\hline Night (\% correct) & 9 & 77.9 (14.3) & 84.8 (11.9) & 0.20 \\
\hline
\end{tabular}

$\mathrm{IOL}$, intraocular lens.

reported. This may be due to the very low luminance levels used in the Mesotest test $\left(0.032 \mathrm{~cd} / \mathrm{m}^{2}\right)$ in our study. The MIOL group also had significantly larger halo areas than the monofocal group, which is in accordance with previous reports of self-reported glare sensitivity, ${ }^{11}$ as well as increased halo size ${ }^{12}$; these differences may reflect the problems reported by MIOL patients with night-time driving. $^{2}$

The literature review done in preparation for this study failed to find any agreed on or scientifically agreed on definition of the terms halo or glare. The tests used, halometry and Mesotest, are considered irregular tests used to try and model the visual experiences of patients after cataract surgery. However, there is no scientifically validated measure or instrument available to measure these phenomena.

What has been observed when testing the MIOL participants is that they describe rings around the test LED.

It is speculated that these rings may in fact be Fraunhoffer diffractive rings associated with a circular aperture of the pupil and the diffractive rings of the IOL. This observation may open up a more productive area of future research to explore as a more scientifically valid explanation of the visual experiences of patient with these IOLs, compared with the more qualitative terms halo and glare.

The defocus curves demonstrated that MIOL subjects had significantly better vision than monoIOL subjects for myopic blur, which is in accordance with previous studies. $^{313-17}$

Significant differences were found-as expected-in the need for near correction with $100 \%$ spectacle freedom for near vision in the MIOL group and two-thirds of the monoIOL group needing spectacles for near-vision tasks.

In terms of vision-related flight simulator tasks, there was no significant difference in performance between MIOL and monoIOL subjects for correct recognition of any of the console-based values, including heading, altitude, speed and fuel flow values, accurately reporting from the airport approach chart or reading off the radio frequency values. Importantly, both IOL groups were able to perform these tasks at relatively high levels of accuracy (many subjects achieving 100\% accuracy), regardless of whether the flight was made in clear daytime or nighttime conditions. These findings are in accordance with those reported for the defocus curves, demonstrating relatively high levels of visual acuity at near and intermediate distances for the MIOL group, with worse results for the monoIOL group. Importantly, the monofocal subjects were able to use near corrections (half-eye reading, bifocals or multifocal spectacles) as required for the flight simulator tasks as indicated in the CASA guidelines. ${ }^{10}$ Even for the lower light levels of the simulated night-time flights, performance was not significantly impaired for either group and no performance differences between groups were evident. It should, however, be noted that 
habitual rather than best-corrected spectacles were used for the vision and flight simulator assessment, which may not reflect the situation for a pilot undergoing medical license assessment.

There was no significant difference in accuracy of colour recognition of runway lights between both groups regardless of light conditions.

This study demonstrated that the ability to complete vision-related flight simulator tasks was not significantly different for the MIOL subjects compared with monofocal IOL subjects. Clearly, comparison of flight simulator performance in a group of pilots with MIOLs to that of pilots with monofocal IOLs would permit inclusion of a wider range of flying tasks, rather than those limited to non-pilots who acted as co-pilots in the simulated flight. However, given that licensed pilots with MIOLs are not permitted to fly, this research was not possible. Nevertheless, we believe that the tasks selected were visually demanding and representative of normal flying conditions as represented in a simulator.

Whereas Australian pilots are not permitted to fly after implantation of MIOLs, the US Federal Aviation Agency (FAA) allows MIOLs in pilots. ${ }^{18}$ The IOL model must be approved for use in the USA and the implantation has to be done at least 3 months prior to the FAA physical examination. In the UK, according to the Civil Aviation Authority, multifocal and bifocal implants are not compatible with pilot certification. Accommodating lenses may be acceptable following a review with a consultant aviation ophthalmology adviser. ${ }^{19}$

Performance-based testing has been helpful in changing aviation policy over concerns about the quality of night vision for other forms of eye surgery, in particular LASIK. ${ }^{20}$ Previously, LASIK was not authorised for aviators in the US Navy and US Air Force because of concern about the postoperative quality of vision. The results of the study were pivotal for the decision to permit LASIK in aviators and astronauts. The US military has meanwhile accepted laser vision correction as a way to improve performance. ${ }^{20}$

In conclusion, this is the first study to explore the flight simulator performance of individuals with MIOLs. The data support previous studies in terms of visual performance with MIOLs. Our findings suggest that the performance of vision-related flight simulator tasks was not significantly impaired in subjects with MIOLs relative to that of age-matched monofocal IOL subjects, who under current licensing arrangements are legally eligible to hold a pilot's license.

Contributors LL planned, conducted and reported the work described in the article and is responsible for the overall content as guarantor.

Funding The study was supported by a research grant from Carl Zeiss Meditec AG.

Competing interests None declared.

Patient consent Obtained.

Ethics approval Queensland University of Technology Human Research Ethics Committee.
Provenance and peer review Not commissioned; externally peer reviewed.

Open Access This is an Open Access article distributed in accordance with the Creative Commons Attribution Non Commercial (CC BY-NC 4.0) license, which permits others to distribute, remix, adapt, build upon this work non-commercially, and license their derivative works on different terms, provided the original work is properly cited and the use is non-commercial. See: http://creativecommons.org/ licenses/by-nc/4.0/

(c) Article author(s) (or their employer(s) unless otherwise stated in the text of the article) 2018. All rights reserved. No commercial use is permitted unless otherwise expressly granted.

\section{REFERENCES}

1. Rochtchina E, Mukesh BN, Wang JJ, et al. Projected prevalence of age-related cataract and cataract surgery in Australia for the years 2001 and 2021: pooled data from two population-based surveys. Clin Exp Ophthalmol 2003;31:233-6.

2. Yamauchi T, Tabuchi H, Takase K, et al. Comparison of visual performance of multifocal intraocular lenses with same material monofocal intraocular lenses. PLoS One 2013;8:e68236.

3. de Silva SR, Evans JR, Kirthi V, et al. Multifocal versus monofocal intraocular lenses after cataract extraction. Cochrane Database Syst Rev 2016;12:CD003169.

4. Shen Z, Lin Y, Zhu Y, et al. Clinical comparison of patient outcomes following implantation of trifocal or bifocal intraocular lenses: a systematic review and meta-analysis. Sci Rep 2017;7:45337.

5. Cochener B, Group CS; Concerto Study Group. Clinical outcomes of a new extended range of vision intraocular lens: International Multicenter Concerto Study. J Cataract Refract Surg 2016;42:1268-75.

6. CASA. DAME Clinical Practice Guidelines: Cataract. Australian Government 2017.

7. van Rijn LJ, Nischler C, Gamer D, et al. Measurement of stray light and glare: comparison of Nyktotest, Mesotest, stray light meter, and computer implemented stray light meter. $\mathrm{Br} J$ Ophthalmol 2005;89:345-51.

8. Buckhurst PJ, Naroo SA, Davies LN, et al. Tablet App halometer for the assessment of dysphotopsia. $J$ Cataract Refract Surg 2015;41:2424-9.

9. McAlinden C, Pesudovs K, Moore JE. The development of an instrument to measure quality of vision: the Quality of Vision (QoV) questionnaire. Invest Ophthalmol Vis Sci 2010;51:5537-45.

10. CASA. Civil Aviation Safety Regulations 1998. Australian Government, 1998;15.

11. Bartol-Puyal FA, Talavero P, Giménez G, et al. Reading and quality of life differences between Tecnis ZCB00 monofocal and Tecnis ZMB00 multifocal intraocular lenses. Eur J Ophthalmol 2017;27:443-53.

12. Puell MC, Pérez-Carrasco MJ, Hurtado-Ceña FJ, et al. Disk halo size measured in individuals with monofocal versus diffractive multifocal intraocular lenses. J Cataract Refract Surg 2015;41:2417-23.

13. Labiris G, Ntonti $P$, Patsiamanidi M, et al. Evaluation of activities of daily living following pseudophakic presbyopic correction. Eye Vis 2017;4:2.

14. Gundersen KG, Potvin R. Comparison of visual outcomes and subjective visual quality after bilateral implantation of a diffractive trifocal intraocular lens and blended implantation of apodized diffractive bifocal intraocular lenses. Clin Ophthalmol 2016;10:805-11.

15. FAA Guide for Aviation Medical Examiners: Decision Considerations. Disease Protocols - Binocular Multifocal and Accommodating Devices. 2016 https://www.faa.gov/about/office_org/headquarters offices/avs/offices/aam/ame/guide/dec_cons/disease_prot/ binocular/ (accessed 23 Aug 2017).

16. CAA Guidance following eye surgery. Refractive Surgery. 2016 https://www.caa.co.uk/Aeromedical-Examiners/Medical-standards/ Pilots- (EASA)/Conditions/Visual/Guidance-following-eye-surgery/ (accessed 23 Aug 2017).

17. Kohnen T, Titke C, Böhm M. Trifocal Intraocular Lens Implantation to Treat Visual Demands in Various Distances Following Lens Removal. Am J Ophthalmol 2016;161:71-7.

18. Mojzis $P$, Majerova K, Hrckova L, et al. Implantation of a diffractive trifocal intraocular lens: one-year follow-up. J Cataract Refract Surg 2015;41:1623-30.

19. Plaza-Puche AB, Alio JL. Analysis of defocus curves of different modern multifocal intraocular lenses. Eur J Ophthalmol 2016;26:412-7.

20. Schallhorn SC, Tanzer DJ, Kaupp SE, et al. Comparison of night driving performance after wavefront-guided and conventional LASIK for moderate myopia. Ophthalmology 2009;116:702-9. 